\title{
Electrochemical Sensors for Berberine Hydrochloride Determination in Commercial Products and Bio-Fluids
}

\author{
Nawal A. Alarfaj, Salma A. Altamimi, Maha F. El-Tohamy*, Fatimah M. AL-Suqayhi \\ King Saud University, College of Science, Department of Chemistry, P.O. Box 22452, Riyadh 11495, \\ Saudi Arabia \\ *E-mail: moraby@ksu.edu.sa
}

doi: $10.20964 / 2021.03 .76$

Received: 21 November 2020 / Accepted: 10 January 2021 / Published: 31 January 2021

\begin{abstract}
The present study describes the development of three electrochemical sensors conducted by the interaction of berberine hydrochloride (BRB) with phosphotungestic acid (plastic membrane), sodium tetraphenyl borate (coated wire), and ammonium reineckate (coated graphite) sensors. Under optimum experimental conditions the effect of membrane content, type of solvent mediator, soaking time, hydrogen ion concentration of the test solutions and the estimation of the analyte in the presence of foreign species were studied. The data confirmed that the developed sensors gave potential responses of $54.10 \pm 0.5,57.00 \pm 0.5$ and $59.00 \pm 0.5 \mathrm{mV}$ decade $^{-1}$ at ambient temperature for (berberinephosphotungstate, BRB-PT), (berberine-tetraphenylborate, BRB-TPB) and (berberine-reineckate, BRB-AR) sensors, respectively, over drug concentration ranges of $1.0 \times 10^{-7}-1.0 \times 10^{-3}, 1.0 \times 10^{-8}-1.0 \times 10^{-}$ 2 and $1.0 \times 10^{-7}-1.0 \times 10^{-2} \mathrm{~mol} \mathrm{~L}-1$ with lower detection limits $5.0 \times 10^{-8}, 5.0 \times 10^{-9}$ and $5.0 \times 10^{-8} \mathrm{~mol} \mathrm{~L}^{-1}$ for the above suggested sensors, respectively. The suggested sensors provide high selectivity, precise and sensitivity for the determination of BRB within the average $\mathrm{pH}$ range 3-9. Validity of the method was performed for the suggested electrochemical probe following ICH guidelines. The suggested sensors were favorably exploited for the estimation of BRB in commercial products and bio-fluids.
\end{abstract}

Keywords: Berberine hydrochloride; Sensors; Plastic membrane; Coated wire; Coated graphite.

\section{$\underline{\text { FULL TEXT }}$}

(C) 2021 The Authors. Published by ESG (www.electrochemsci.org). This article is an open access article distributed under the terms and conditions of the Creative Commons Attribution license (http://creativecommons.org/licenses/by/4.0/). 